\title{
Effect of an inhaled antihistamine (clemastine) as a bronchodilator and as a maintenance treatment in asthma
}

\author{
MARTYN R PARTRIDGE AND KENNETH B SAUNDERS
}

From the Department of Medicine, Middlesex Hospital and Medical School, London W1, UK

\begin{abstract}
Although intravenous chlorpheniramine can cause bronchodilatation, oral and parenteral antihistamines have not proved useful in treating asthma. Inhaled antihistamines may cause throat irritation, but a recent study of the antihistamine, clemastine, showed it to be an effective bronchodilator without irritant effects. We have extended these studies to determine the site of action of inhaled clemastine and to assess its potential usefulness both as a bronchodilator and as a maintenance treatment. Eleven stable asthmatic patients received inhaled clemastine and placebo and the effect was assessed by serial maximum expiratory flow volume (MEFV) curves breathing air and a helium/oxygen $\left(\mathrm{He} / \mathrm{O}_{2}\right)$ mixture. There was no significant improvement in peak flow rates during air breathing after clemastine and no significant difference between the responses to drug and placebo. Minor but significant changes were seen in some flow measurements on the downslope of the MEFV curve during air and $\mathrm{He} / \mathrm{O}_{2}$ breathing, and these are tentatively ascribed to a dilating effect of clemastine on peripheral airways where flow is laminar. Subsequent administration of inhaled isoprenaline showed the patients to be still capable of significant bronchodilatation. The addition of clemastine, from a pressurised aerosol, to the patients' therapeutic regimen for two weeks was no more effective than placebo in controlling airflow obstruction, and did not reduce the need for standard bronchodilators. In our patients clemastine was not a clinically useful bronchodilator either acutely or as a maintenance treatment for asthma.
\end{abstract}

In asthmatic patients the bronchial smooth muscle is hyperreactive to histamine released by allergic reactions, but oral and parenteral antihistamine have not proved useful in treating asthma, although intravenous chlorpheniramine can produce bronchodilatation (Popa, 1977). Aerosols of antihistamine may cause throat irritation, but a recent study (Nogrady et al, 1978) of the $\mathrm{H}_{1}$-receptor blocking antihistamine, clemastine, showed it to have no irritant effects when inhaled. In a double-blind study 12 patients (six atopic) who had recovered from acute severe asthma were given $1 \mathrm{ml}$ clemastine $0.05 \%$ in saline, salbutamol $0.05 \%$, or physiological saline by aerosol inhalation. Both clemastine and salbutamol caused significant bronchodilatation, and there was no significant difference between them. Subsequent work (Nogrady and Bevan, 1978) has confirmed that the broncho- dilator properties of clemastine are not related to any anticholinergic action.

We have extended these studies to determine the site of action of inhaled clemastine and to assess its potency, both acutely and as a maintenance treatment.

\section{Methods}

NORMAL SUBJECTS

Three normal subjects inhaled $0.2 \mathrm{mg}$ clemastine or physiological saline placebo from a pressurised aerosol and had serial measurements of airways resistance and total lung capacity measured in the body plethysmograph for two hours after administration of drug or placebo. A further six normal subjects performed MEFV curves breathing air and $\mathrm{He} / \mathrm{O}_{2}$ without therapeutic intervention to assess degree of density dependence of flow in normal subjects in our laboratory. 


\section{ACUTE STUDIES IN ASTHMATIC PATIENTS}

Eleven patients took part, five men and six women with an age range of 20-74 (mean 46). Five patients had positive skin tests to various allergens, and all were on regular beclomethasone inhalations with three on additional oral corticosteroids (two patients taking $5 \mathrm{mg}$ prednisolone daily and one taking $2 \mathrm{mg}$ prednisolone daily). One patient was a smoker and 10 were non-smokers (five lifelong). Two of the patients were studied while in hospital for stabilisation of poorly controlled asthma, but the rest were outpatients in a relatively stable condition. All gave informed consent to the study, which had been approved by the Middlesex Hospital Clinical Investigations Panel.

Each patient attended the laboratory on two afternoons having taken no bronchodilator or beclomethasone for 12 hours. Maximal expiratory flow volume (MEFV) curves were obtained from two consistent forced vital capacity manoeuvres into an Ohio 840 spirometer, with volume and flow outputs linked to an Electronics for Medicine DR8 photographic recorder. Peak flow rate (PFR) and the maximal expiratory flow rate at $25 \%$ and $50 \%$ observed vital capacity $\left(\operatorname{Vmax}_{25}\right.$ and $V \max _{50}$ ) were recorded at BTPS from the MEFV curve. A further two MEFV curves were taken after the subject had breathed for three minutes a mixture of $79 \%$ helium and $21 \%$ oxygen (Despas et al, 1972). Initial studies showed that even with quite severe airflow obstruction three minutes $\mathrm{He} / \mathrm{O}_{2}$ breathing was sufficient for end-tidal nitrogen concentration to be less than $5 \%$ when measured with a mass spectrometer. Recordings during air breathing were made at $-15,-5,+5,+15,+30,+45,+60,+90$, and +120 minutes with inhalation of drug or placebo at zero time, and $\mathrm{He} / \mathrm{O}_{2}$ measurements were made in addition at $-15,-5,+30,+60$, and +120 minutes. Nine patients received $2 \mathrm{ml} 0.05 \%$ clemastine in saline or $2 \mathrm{ml}$ physiological saline, in double-blind fashion and randomised order via an air-driven Wright nebuliser. Two patients received $\mathbf{0 . 2} \mathrm{mg}$ clemastine or saline as a pressurised aerosol. (No differences emerged in the result between these two groups of patients, and the results were therefore analysed together.) At the end of 120 minutes' observation on each day the patients were given $0.8 \mathrm{mg}$ isoprenaline by inhalation as a pressurised aerosol and further MEFV curves were recorded five minutes later. Flow rate results are expressed as a percentage of the bronchodilatation achieved after isoprenaline. The response to drug or placebo at each time was defined as the increase in this percentage from the baseline value. Statistical analysis was by the음 paired t-test. Predicted normal values are those of $\overline{\frac{\omega}{\omega}}$ Cherniack and Raber (1972).

\section{MAINTENANCE STUDY}

Six asthmatic patients ( 4 men, 2 women) also took $\vec{\circ}$ part in the trial of clemastine as a maintenance $\vec{\omega}$ treatment. Ages ranged from 26-74 (mean 50.5). All of these patients took regular beclomethasone $\vec{x}$ inhalations, and one took $5 \mathrm{mg}$ oral prednisolone $\omega_{+}$ a day. These drugs plus their normal bronchodilator treatment were continued throughout the trial, but in addition the patients took two puffsof clemastine $(0.2 \mathrm{mg})$ or saline from a pressurised음 aerosol four times a day, each for two weeks in adouble-blind fashion. A daily diary was kept on which was recorded a symptom score for wheeze, $\mathbb{\mathbb { \Phi }}$ cough, and exercise tolerance. Peak flow record- $\frac{3}{6}$ ings were measured with a peak flow gauge and음 the best of three readings were recorded on wak- $\vec{\varphi}$ ing in the morning, at 1800, and at bed time. The number of puffs of bronchodilator used during the 24-hour period was also recorded. The variabilityo of asthma was calculated for each day with the formula:

$$
\text { Variability }=\frac{\text { Best PFR-worst PFR }}{\text { Best PFR }} \times 100
$$

Taking the last 10 days of each two-week period to 3 avoid a carry-over effect, we compared the cal-? culated variability and measured PFR at the three? recording times with paired ' $t$ ' tests.

\section{Results}

\section{NORMAL SUBJECTS}

No significant changes in airway resistance or 3 total lung capacity were seen during two hours'o observation in three normal subjects after either $>$ clemastine or physiological saline inhalation.

Six normal non-smoking subjects all exhibited increased flow rates after breathing the $\mathrm{He} / \mathrm{O}_{2}$ mixture compared with the values obtained while 0 breathing air. The mean percentage increase in $N_{\omega}^{N}$ $\operatorname{Vmax}_{25}$ was $33 \%$ and in $\operatorname{Vmax}{ }_{50}$ it was $39 \%$.

\section{ACUTE STUDIES IN ASTHMATIC PATIENTS}

Details of the 11 asthmatic patients studied and $\stackrel{\infty}{?}$ their mean baseline and predicted values for ${ }_{-}^{-}$ PFR, Vmax ${ }_{50}$, and $\operatorname{Vmax}_{25}$ are shown in the table. $\frac{\mathrm{O}}{\mathbb{N}}$ No side effects were reported after either clem- $\frac{?}{\Phi}$ astine or physiological saline inhalation. One nor-@ mal subject and one patient noted a different? taste after clemastine. 
Characteristics of asthmatic patients studied and mean baseline and predicted values of PFR, Vmax m, $_{5}$, and Vmax ${ }_{25}$ breathing air

\begin{tabular}{|c|c|c|c|c|c|c|c|c|c|}
\hline \multirow{2}{*}{ Patient } & \multirow{2}{*}{ Age } & \multirow{2}{*}{$\operatorname{Sex}$} & \multirow{2}{*}{ Skin tests } & \multicolumn{2}{|c|}{ Peak flow rate $1 / \mathrm{sec}$} & \multicolumn{2}{|l|}{$V \max _{50} l / \mathrm{sec}$} & \multicolumn{2}{|l|}{$V \max _{25} l / s e c$} \\
\hline & & & & $\begin{array}{l}\text { Mean baseline } \\
\text { value }\end{array}$ & Predicted & $\begin{array}{l}\text { Mean baseline } \\
\text { value }\end{array}$ & Predicted & $\begin{array}{l}\text { Mean baseline } \\
\text { value }\end{array}$ & Predicted \\
\hline $\begin{array}{r}1 \\
2 \\
3 \\
4 \\
5 \\
6 \\
7 \\
8 \\
9 \\
10 \\
11\end{array}$ & $\begin{array}{l}74 \\
71 \\
56 \\
58 \\
33 \\
52 \\
56 \\
58 \\
26 \\
20 \\
23\end{array}$ & $\begin{array}{l}\mathbf{M} \\
\mathbf{M} \\
\mathbf{M} \\
\mathbf{F} \\
\mathbf{F} \\
\mathbf{F} \\
\mathbf{F} \\
\mathbf{F} \\
\mathbf{F} \\
\mathbf{M} \\
\mathbf{M}\end{array}$ & $\begin{array}{l}- \\
\overline{+} \\
\bar{t} \\
\overline{-} \\
- \\
\bar{t} \\
+ \\
+ \\
+\end{array}$ & $\begin{array}{l}4 \cdot 82 \\
3 \cdot 05 \\
5 \cdot 22 \\
2 \cdot 63 \\
5 \cdot 07 \\
3 \cdot 89 \\
4 \cdot 49 \\
1 \cdot 36 \\
6 \cdot 25 \\
5 \cdot 15 \\
3 \cdot 20\end{array}$ & $\begin{array}{l}7 \cdot 80 \\
8 \cdot 31 \\
8 \cdot 09 \\
5 \cdot 76 \\
6 \cdot 57 \\
6 \cdot 14 \\
5 \cdot 80 \\
5 \cdot 94 \\
6 \cdot 79 \\
9 \cdot 96 \\
9 \cdot 32\end{array}$ & $\begin{array}{l}1.83 \\
0.33 \\
0.56 \\
0.46 \\
1.32 \\
1.36 \\
0.85 \\
0.35 \\
2.57 \\
1.55 \\
0.92\end{array}$ & $\begin{array}{l}4 \cdot 39 \\
4 \cdot 68 \\
4 \cdot 87 \\
3 \cdot 92 \\
4 \cdot 76 \\
4 \cdot 25 \\
3 \cdot 97 \\
4 \cdot 05 \\
5 \cdot 00 \\
6 \cdot 43 \\
6.07\end{array}$ & $\begin{array}{l}0.50 \\
0.18 \\
0.23 \\
0.19 \\
0.58 \\
0.44 \\
0.41 \\
0.17 \\
1.02 \\
0.87 \\
0.47\end{array}$ & $\begin{array}{l}1.25 \\
1.48 \\
1.96 \\
1.66 \\
2.62 \\
1.94 \\
1.73 \\
1 \cdot 71 \\
3.69 \\
3.70 \\
3.43\end{array}$ \\
\hline
\end{tabular}

\section{FLOW RATES BREATHING AIR}

Mean baseline values were similar on drug and placebo days for PFR, Vmax $\operatorname{man}_{25}$, and $V \max _{50}$. Figure 1 shows the mean values for these flow rates expressed as a percentage of the postisoprenaline value for two hours after clemastine or placebo. The PFR did not increase significantly compared with baseline at any time after either clemastine or placebo, nor at any time was there a significant difference between the responses to clemastine or placebo. $V \max _{50}$, however, increased significantly within 15 minutes of inhalation of clemastine, but this was only significantly better than the response to placebo at 120 minutes $(P<0.05)$. Similarly, $\operatorname{Vmax}_{2.5}$ increased significantly ccmpared with baseline within 45 minutes of clemastine inhalation, but at no time was there a significant difference between the response to drug or placebo. There were no significant changes in vital capacity after either drug or placebo.

FLOW RATES BREATHING HE $/ \mathrm{o}_{2}$ (fig 2 )

Again mean baseline values were similar on drug and placebo days for PFR and $\operatorname{Vmax}_{25}$ breathing $\mathrm{He} / \mathrm{O}_{2}$, but $\operatorname{Vmax}_{50}$ was significantly higher $(\mathrm{P}<0.05)$ on the placebo day than on the day clemastine was given. PFR, $\operatorname{Vmax}_{25}$, and $\mathrm{Vmax}_{50}$ increased significantly by 30 minutes after clemastine compared to the baseline value, but these results were only significantly different to the placebo response at 60 minutes for $\mathrm{Vmax}_{50}$ $(\mathrm{P}<0.02)$, at 120 minutes for PFR $(\mathrm{P}<0.05)$, and not at any other time.

Eight of the eleven patients showed a greater than $20 \%$ increase in $\operatorname{Vmax}_{50}$ when breathing $\mathrm{He} / \mathrm{O}_{2}$ as compared to air, and would be classified as "responders" by Despas et al (1972). If peak flow rates were used nine out of 11 were responders.

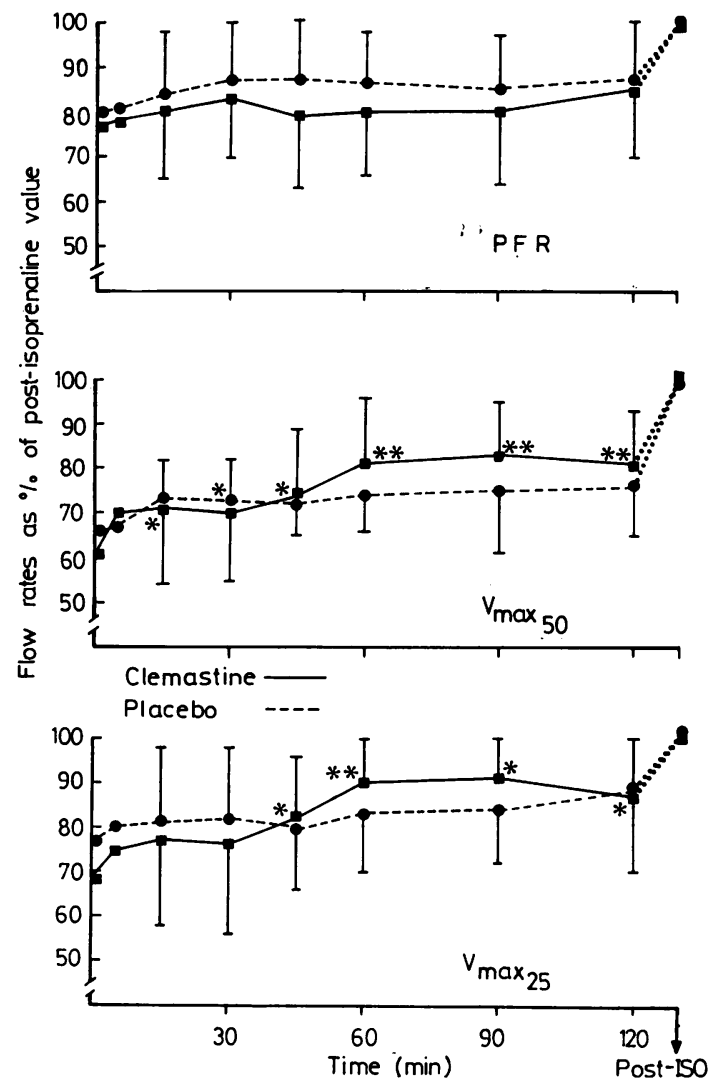

Fig 1 Mean values of PFR, $V \max _{50}$, and $V$ max $_{55}$ (with 1 standard deviation) breathing air, expressed as a percentage of post-isoprenaline value for two hours after inhalation of clemastine or placebo. Values differing significantly from baseline are marked $*(\mathrm{P}<0.05){ }^{* *}(\mathrm{P}<0.005)$. Response of $\operatorname{Vmax}_{50}$ was significantly higher after drug than placebo at 120 minutes, but at no other time. There were no significant placebo-drug differences for PFR and $V \max _{25}$. 

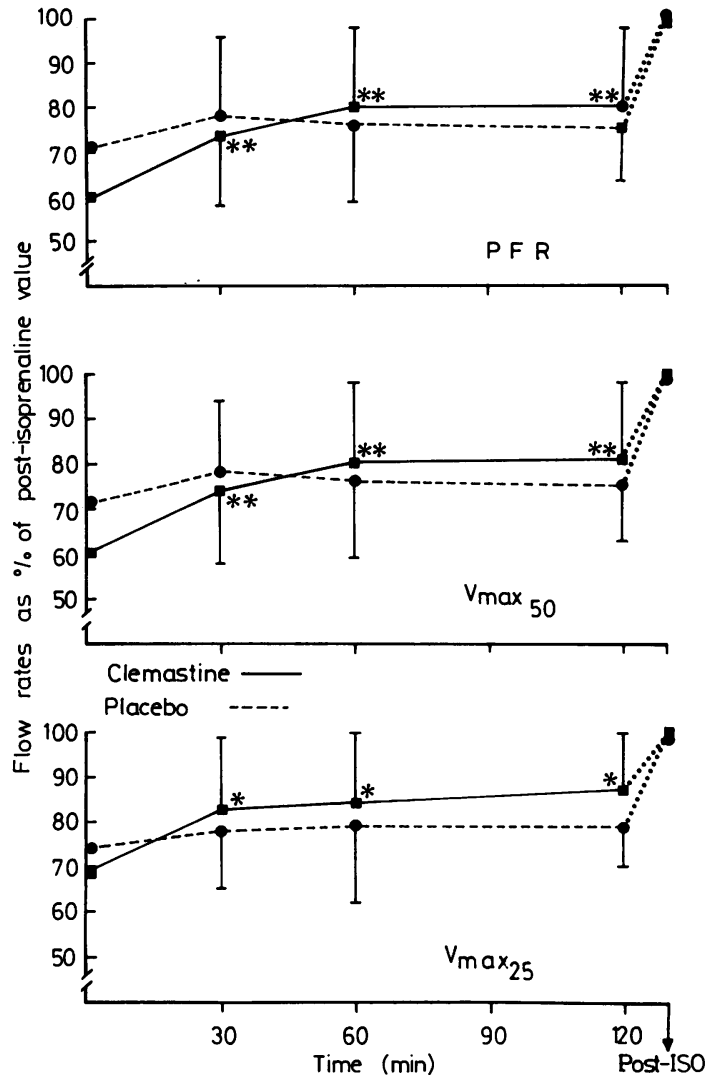

Fig 2 Mean values of PFR, $V \max _{50}$, and $V \max _{25}$ (with 1 standard deviation) breathing $\mathrm{He} / \mathrm{O}_{2}$ expressed as a percentage of post-isoprenaline value for two hours after inhalation of clemastine or placebo. Values differing significantly from baseline are marked $*(\mathrm{P}<0.05) * *(\mathrm{P}<0.005)$ Response of $P F R$ was significantly higher after drug than placebo at 120 minutes but at no other time. $V \max _{50}$ was significantly higher after drug than placebo at 60 minutes but at no other time. There were no significant placebo-drug differences for $V \max _{25}$.

After isoprenaline inhalation there was a significant increase in all flow rates both on drug and placebo days whether breathing air or the $\mathrm{He} / \mathrm{O}_{2}$ mixture (figs 1 and 2). It appeared to have no effect on the degree of density dependence of flow as judged by PFR and $V_{m a x}$. Using values for $V \max _{25}$, however, the response to $\mathrm{He} / \mathrm{O}_{2}$ breathing (defined as the percentage increase in flow on $\mathrm{He} / \mathrm{O}_{2}$ breathing) was significantly greater after isoprenaline than before $(P<0.01)$ (fig 3 ).

\section{MAINTENANCE STUDY}

In the maintenance treatment studies the mean variability of the air flow obstruction in each of
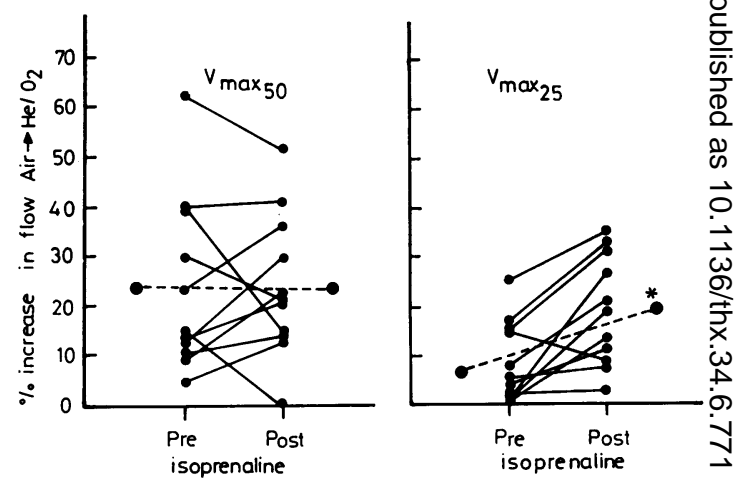

Fig 3 Percentage increases in flow rates breathing $\mathrm{He} / \mathrm{O}_{2}$ compared to air, before and after inhalation of $\rightarrow$ isoprenaline $\left({ }^{*} \mathrm{P}<0.01\right)$.

the six asthmatic patients during the last 10 days of both drug and placebo periods ranged from? $10 \cdot 1-36.4 \%$ (mean $19 \cdot 0 \pm 7 \cdot 7$ ). The mean morningo peak flow rates during the placebo period werê $295 \pm 138$ and during the clemastine period 294 132. The results at 2200 for PFRs were $345 \pm 153$ during placebo and $352 \pm 147$ during the clemastine period. Analysis of the individual results showe no statistical differences between the treatment ox placebo periods either as judged by PFR and variability or by symptom score and number op dosages of bronchodilator required.

\section{Discussion}

Despite using a dose of inhaled antihistamine twice as large as that used previously (Nogrady et $a l, 1978)$ we have been unable to show that clemastine was a useful bronchodilator in our patients. Serial PFRs breathing air showed no improvement after inhalation of the drug. A minor but significant effect, however, has been observed on some of the flow variables which (for the following reasons) we suggest may have been due to a minor degree of small airway dila tation. Flow limitation in small airways reducesu flow rates at low lung volumes more than at high and mid-lung volumes (Bass, 1973). In our patientso $\operatorname{Vmax}_{25}$ and $\mathrm{Vmax}_{50}$ breathing air improved significantly after clemastine but without a corre sponding improvement in PFR. This would b£ consistent with some reduction in small airway flow limitation after the drug. This suggestion $\bar{b}$ may be corroborated by the flow rate response tod $\mathrm{He} / \mathrm{O}_{2}$ breathing. Improvement of flow rates dureD ing $\mathrm{He} / \mathrm{O}_{2}$ breathing has been attributed (Despas et $a l, 1972)$ to the major site of flow limitation being in larger airways with low total crosse 
sectional area and a density-dependent flow regimen due to turbulent flow and convective acceleration. Absence of response is attributed to obstruction principally in small peripheral airways with large total cross-sectional area and laminar flow. Thus an increase in the response to $\mathrm{He} / \mathrm{O}_{2}$ breathing after therapeutic intervention would suggest a shift of the major site of airflow limitation away from the small airways towards the larger airways where a turbulent (density dependent) flow regimen predominates. In our patients more significant increases in PFR, $\mathrm{Vmax}_{50}$, and $\operatorname{Vmax}_{25}$ occurred on $\mathrm{He} / \mathrm{O}_{2}$ breathing than during air-breathing after the inhalation of clemastine. Thus although clemastine had a minor overall effect in our patients some small airway dilatation may have occurred.

The reasons for the differences between this and the previous study (Nogrady et al, 1978) are not clear. Their patients had recovered to a relatively stable condition from an episode of severe asthma, while most of our subjects were relatively stable outpatients, although still capable of significant bronchodilatation as judged by their response to isoprenaline (figs 1 and 2). Age and atopic state were similar in both studies, and although concurrent treatment is not mentioned in their report, it seems likely that if their patients were recovering from an acute episode of asthma more could have been taking oral steroids than the few who were in our group. Their patients were studied in the morning when spontaneous diurnal improvement may be expected, and a prominent placebo response was recorded. While mean percentage changes for the whole group were statistically better during the period of observation after clemastine than after placebo, they did not comment on their table of individual baseline and peak values of $\mathrm{FEV}_{1}$ and PFR after clemastine and placebo, which shows individual maximal responses as opposed to mean changes with time. Analysis of those figures suggest that maximal values after clemastine were greater than placebo in only eight of 12 patients and in some only slightly greater. Moreover, we find it impossible to reconcile in their table 2 a baseline to peak mean percentage change after placebo of $27.9 \%$ with, in their table 1 and fig 1 , a mean maximal change of only $15 \%$ at any given time. In their studies clemastine appeared to have a later onset of action than salbutamol and duration of action was probably longer, and for this reason we assessed the value of clemastine as a maintenance treatment when delivered from a pressurised aerosol. The dosage chosen $(0.2 \mathrm{mg})$ is a reasonable extrapolation for a pressurised aerosol dosage compared with the $0.5 \mathrm{mg}$ thought to be effective via a nebuliser (Nogrady et al, 1978). (Compare salbutamol 200-400 $\mu \mathrm{g}$ from a pressurised aerosol and $2 \cdot 5-5 \mathrm{mg}$ from a wet nebuliser). The results from our maintenance treatment trial may be criticised because of the continuation of other treatments (beclomethasone \pm oral corticosteroids) but in view of our disappointing results in the acute study it was not thought to be ethically justified to withhold the other treatments. In only one patient, however, did the peak flow rate at any time approach the predicted normal value, and the mean variability of $19 \%$ suggests that there was adequate scope for further improvement with clemastine, but this did not occur.

The proportion of our asthmatic patients with $20 \%$ increased flow rates on $\mathrm{He} / \mathrm{O}_{2}$ breathing was similar to that reported previously in stable asthmatic patients (Chan-Yeung et al, 1976; Wellman et al, 1976). The relation, however, between degree of airflow obstruction and presence of $\mathrm{He} / \mathrm{O}_{2}$ response was not so evident.

Isoprenaline inhalation was associated with significant increases in flow rates at all lung volumes and a significant improvement in vital capacity. Ingram et al (1977) showed that in normal subjects isoprenaline appears to dilate preferentially small peripheral airways, and work from the same laboratory (Wellman et al, 1976) suggested that the same is true for patients with airflow obstruction, and that the degree of response to bronchodilators correlates with the presence of increased density dependence of flow after bronchodilators. Despite the fact that our patients all exhibited a pronounced bronchodilator response to isoprenaline the degree of increased density dependence of flow after isoprenaline was not significant for $\operatorname{Vmax}_{50}$, suggesting that although isoprenaline may preferentially dilate small airways, it must have a significant effect on large airways as well.

The use of t-tests in this study may be criticised because with small numbers it is impossible to be sure that the data is normally distributed. We repeated the analysis with the sign test (Geigy Scientific Tables, 1970), which is distribution-free but less powerful than the t-test, and found that eight fewer marked points in figs 1 and 2 attained significance at the $5 \%$ level, and there were then no significant drug-placebo differences. Thus our arguments above are unaltered.

Comparison of studies such as these made on different days may be difficult because the lability of asthma causes baseline measurements to vary. It is then more logical to use the values after maximal bronchodilatation as the standard for 
normalisation, since they should show less variability, as they did in this study. Baseline predrug measurements thus adjusted were not significantly different on the two days, with the single exception of $\mathrm{Vmax}_{50}$ on $\mathrm{He} / \mathrm{O}_{2}$.

We conclude that in our patients clemastine when given by the inhaled route did not prove to be a clinically effective bronchodilator, and neither has it been shown to be of value as a maintenance treatment in asthma.

We are grateful to Sandoz Products Ltd for supplies of clemastine. M R Partridge holds a Sir Jules Thorn Research Fellowship. The work was supported by an equipment grant No 549 from the British Heart Foundation.

\section{References}

Bass, H (1973). The flow volume loop: normal standards and abnormalities in chronic obstructive pulmonary disease. Chest, 63, 171-176.

Chan-Yeung, M, Abboud, R, Ming Sound Tsao, and Maclean, L (1976). Effect of helium on maximal expiratory flow in patients with asthma before and during induced bronchoconstriction. American Review of Respiratory Disease, 113, 433-443.

Cherniack, R M, and Raber, M B (1972). Normal standards for ventilatory function using an automated wedge spirometer. American Review of Respiratory Disease, 106, 38-46.
Despas, P J, Leroux, M, and Macklem, P T (1972) Site of airway obstruction in asthma as determinef by measuring maximal expiratory flow breathing air and a helium oxygen mixture. Journal of Clinica Investigation, 51, 3235-3243.

Geigy Scientific Tables (1970). 7th edn, p 104. Geigîs Pharmaceuticals, Macclesfield.

Ingram, $\mathbf{R} \mathbf{H}$, Wellman, $\mathbf{J} \mathbf{J}$, McFadden, $E \mathbf{R}$, and Mead, J (1977). Relative contributions of large and small airways to flow limitation in normal subjecto before and after atropine and isoproterenol. Journa of Clinical Investigation, 59, 696-703.

Nogrady, S G, and Bevan, C (1978). Inhaled anti $\underset{\oplus}{\oplus}$ histamines-bronchodilatation and effects on hista? mine and methacholine-induced bronchoconstriction $\checkmark$ Thorax, 33, 700-704.

Nogrady, S G, Hartley, J P R, Handslip, P D J, anक Hurst, N P (1978). Bronchodilatation after inhalation of the antihistamine clemastine. Thorax, 33: 479-482.

Popa, V T (1977). Bronchodilating activity of an $\mathrm{H}_{5}^{\Phi}$ blocker, chlorpheniramine. Journal of Allergy and Clinical Immunology, 59, 54-63.

Wellman, J J, McFadden, E R, and Ingram, R (1976). Density-dependence of maximal expiratorye flow rates before and after bronchodilators in patients with obstructive airways disease. Clinicab Science and Molecular Medicine, 51, 133-139.

Requests for reprints to: Dr M R Partridge, Depart: ment of Medicine, Sir Jules Thorn Institute of Clinica $B$ Science, Middlesex Hospital, Mortimer Street, London W1. 